\title{
The Effect of Insulation Defects on Electric and Magnetic Field Distributions in Power Cables
}

\author{
Cihat Cagdas UYDUR*, Oktay ARIKAN, Ozcan KALENDERLI
}

\begin{abstract}
In this article, electrical and magnetic field analysis in XLPE insulated power cables is performed. The defects that may occur in the insulation material have been tried to be realized considering different conditions. A lot of variations have been obtained by changing the location of the defect in the insulation material, the shape of the defect, the size of the defect and the type of the defect. The effect of all the factors that make up the defect on the distribution of the electric field and magnetic field is shown and the causes of malfunction in the cable are examined. The electric field analysis for $1 \times 240 / 25 \mathrm{~mm}^{2}$ was performed by using different forms with equal areas. The magnetic field analysis was performed for balanced and unbalanced load cases to $3 \times(1 \times 240 / 25) \mathrm{mm}^{2}$ and $3 \times 240 / 25 \mathrm{~mm}^{2}$ cable with XLPE insulation.
\end{abstract}

Keywords: aging; electric field; insulation defect; magnetic field; XLPE cable

\section{INTRODUCTION}

Working underground with high voltage reveals insulation problems that occur on the distribution cable. In order to cope with this problem, it is necessary that the selection of the insulation materials be done carefully, the production steps be followed qualitatively and smoothly. Partial discharges shorten the life of the cable when the penetration value of the electric field particles exposed by the foreign particles in the cable insulation material exceeds the value of the dielectric strength and causes the damage of cables, cable joints, and terminations due to aging problems $[1,2]$.

The main insulation layer is the most important layer of the high voltage cable, and the quality of this material directly affects the cable life [3, 4]. In addition, it is known that impurities, voids and associated partial discharges in the insulation have an effect on cable life. Many studies in the literature have been done on the effects of gaps in insulation on partial discharge and cable life. Partial discharge occurs when the electric field exposed to the air gaps in the cable exceeds the breakdown strength of the air. This discharge can lead to deterioration of the insulation material and, accordingly, to complete breakdown, which can pose a hazard to the entire system [5-7]. The noticeable effect of these defects is to make heterogeneous the insulation in the area where they happened and cause a distortion in the electric field distribution [9, 10]. Power transmission and distribution system, especially in urban area, has been widely using XLPE cables since about 40 years ago. Nowadays, some XLPE cables have been operated for about 30 years, almost the designed lifetime. Hence, it is important to understand voltage withstanding the stress of aged XLPE cable to ensure reliable operation and minimized replacement planning for the aged XLPE cable $[12,13]$. The defects in the cable insulation material should be examined in more detail in terms of form [14, 15].

Illias and his team experimentally examined partial discharges formed by spherical cavities in solid insulators in 2009 and made definitions from the results of measurement of partial discharges $[16,17]$. Then, a similar study was modelled by the same team and the experiments with simulation results were overlapped. Partial discharges that have occurred have been tried to be defined as a function that depends on temperature and applied voltage $[18,19]$. The results have been tested in conditions where more than one spherical cavity is in the dielectric material and the results have been interpreted as reasonable [20,21]. In the light of this information, studies on the definition and classification of partial discharges have been continued by examining under different voltage types such as impact voltage and damped voltage [22, 23]. The team of the same authors, who continue their work on partial discharge, examined the partial discharge events caused by $132 \mathrm{kV}$ cable termination and cable joint failures and contributed to the development of designs [24, 25]. It continued modelling studies on cable joints and terminations of different geometries and examined the effect of dielectric constant on partial discharge formation and measurement results [26, 27]. Finally, in the articles of the same team published in 2015 and 2016, they created a cable model using different insulating materials and examined the partial discharges created by the spaces with different geometries in the cable [28, 29].

In order to support the studies in the literature, this study was carried out to examine the situations in which different materials are present in defects of different forms.

In this study, the geometrical dimensions of high voltage cables with $20,3 / 35 \mathrm{kV}$, single-core, XLPE insulated, $240 \mathrm{~mm}^{2}$ conductor cross section, which is frequently used in electrical power distribution, are determined through real examples. In the following part of the study, $1 \times 240 / 25 \mathrm{~mm}^{2}$ will be named CableSC and $3 \times$ $240 / 25 \mathrm{~mm}^{2}$ will be named CableTC. Within the cable in different co-ordinates, the effect of various cable defects on the distribution of electric and magnetic fields with different scenarios has been investigated. In the first scenario, the electric field analysis for the CableSC was performed by using different forms with equal areas as the magnetic field was not changed. In the second scenario, magnetic field analysis was performed for balanced and unbalanced load cases for CableSC and CableTC. In order to see the effect of the unbalanced condition noticed by the measurements made in the field, a simulation model was created by accepting that there was a lot of unbalanced. Balanced overload can be defined as current flow of $575 \mathrm{~A}$ through all cables, unbalanced load can be defined as 
current flow of $460 \mathrm{~A}-575 \mathrm{~A}-690$ A through cables. As a result of the examinations, comparative results were given for each fault relative to the faulty cable and a general evaluation was made for all the scenarios in the evaluation section. In this study, a package program named Finite Element Method Magnetics (FEMM) is used.

\section{METHOD}

In analytical solutions used in high voltage technique, one of the most important problems is the electric field analyses that require solutions of Laplace and Poisson equations. It is difficult to solve analytically, especially in cases with complex geometry. High voltage cables have a cylindrical structure and field equations of the cylindrical coordinate system are used for their analysis. In Eq. (1) and Eq. (2), electric and magnetic field expressions are given for the single core cable, respectively [30].

$$
E=\frac{1}{r} \frac{U_{0}}{\ln \frac{r_{2}}{r_{1}}}
$$

where $r(\mathrm{~mm})$ is the radius to be electric field calculated, $r_{1}$ $(\mathrm{mm})$ is the radius of the inner conductor of the cable, $r_{2}$ $(\mathrm{mm})$ is the radius of the cable shield, $U_{0}(\mathrm{kV})$ is the cable phase-neutral (or earth) voltage.

$$
B=\frac{\mu I}{5 \pi r}
$$

where $r$ is the radius to be magnetic field calculated, $I$ is current flowing through the cable, $\mu$ is the relative permeability of magnetic ambient [30]. Analytical computation of electrical and magnetic fields is also difficult, especially in the case of such defects, as the foreign materials or other materials contained in the cable insulation material are not predictable to be cylindrical or spherical. For this reason, it is more convenient to use numerical methods. In the finite element method, the boundaries of the problem define the region to be analyzed. This closed bounded region is expressed by a function, called domain variable, defined at every point inside and at its boundaries. The field variable is the function that tries to find an unknown value in the solution region. If the field is a variant, the approximation is defined as a function [30]. The approximation function transforms the field variable function into a set of closed algebraic equations of independent variables. In order to be able to use the finite element method in the light of the above:

- The area to be treated consists of a closed area or volume,

- Identification of the physical properties of all materials in the problem,

- The function whose value is tried to be found must be defined at every point in the system.

In the defined system, the system is divided into finite elements so that the solution can be done according to the finite element method. In this study, triangular finite element with 3 node points is used. This finite element type is the simplest 2D finite element and a closed element.

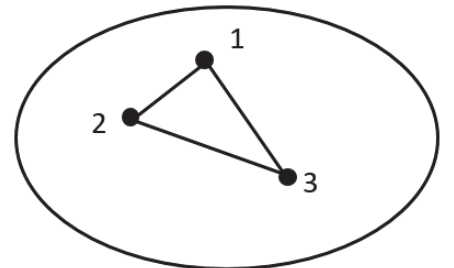

Figure $1 \mathrm{~A}$ triangular finite element identified in the solution region

The corner points of the triangle ending element are called the node points, and the approach functions are defined for these points. Points inside the element are called inner points. Field variables of points that are not node points are found by interpolation of known points at node points. As can be seen in Fig. 1, only triangular elements have nodal points numbered 1, 2, and 3 at their corners. In this case, approximate expression:

$V(x, y)=N_{1}(x, y) \varphi_{1}+N_{2}(x, y) \varphi_{2}+N_{3}(x, y) \varphi_{3}$

Here, $\varphi_{1}, \varphi_{2}, \varphi_{3}$ field variables are defined as interpolation approximation functions. Other functions, $N_{1}(x, y), N_{2}(x, y), N_{3}(x, y)$ functions are form functions.

\section{ANALYSIS AND SIMULATION RESULTS}

All scenarios carried out in the study were analyzed under the cylindrical coordinate system with $1000 \mathrm{~mm}$ cable depth, assuming that there is nominal voltage and nominal current flow. The main reason for not using $3 \mathrm{D}$ in the simulation study is that it is very difficult to create the defect in the cable and the simulation study requires strong equipment. In this context, the reasons for using $2 \mathrm{D}$ can be shown as being easy to implement and choosing the same method as current studies in the literature.

In this section, cable geometries are defined on the FEMM package program for CableSC and CableTC. The parameters related to the cable to be analyzed, and the electrical properties of the materials used in the modelling of cable defects are given in Tab. 1 and Tab. 2 .

Table 1 Parameters of XLPE cable [3]

\begin{tabular}{|l|c|c|}
\hline \multicolumn{1}{|c|}{ Parameter } & CableSC & CableTC \\
\hline Rated voltage $/ \mathrm{kV}$ & 35 & 35 \\
\hline Conductor cross section $/ \mathrm{mm}^{2}$ & 240 & 240 \\
\hline Diameter of conductor $/ \mathrm{mm}$ & 18,8 & 18,8 \\
\hline Semiconductor diameter $/ \mathrm{mm}$ & 20 & 20 \\
\hline Outer diameter of insulation $/ \mathrm{mm}$ & 38 & 38 \\
\hline Outer diameter of sheath / $\mathrm{mm}$ & 46 & 99 \\
\hline Shield cross section $/ \mathrm{mm}^{2}$ & 25 & 25 \\
\hline Current carrying capacity / A & 575 & 575 \\
\hline
\end{tabular}

Table 2 Material properties of the defection medium [3]

\begin{tabular}{|c|c|c|c|}
\hline Material & $\begin{array}{c}\text { Dielectric } \\
\text { strength } \\
E_{\mathrm{d}} / \mathrm{kV} / \mathrm{cm}\end{array}$ & $\begin{array}{c}\text { Relative } \\
\text { permittivity } \\
\varepsilon_{\mathrm{r}}\end{array}$ & $\begin{array}{c}\text { Relative } \\
\text { permeability } \\
\mu_{\mathrm{r}}\end{array}$ \\
\hline XLPE & 1000 & 2,3 & 1 \\
\hline Air & 30 & 1 & 1 \\
\hline Fiber & 150 & 4 & 1 \\
\hline $\begin{array}{c}\text { Transformer } \\
\text { Oil }\end{array}$ & 100 & 4,5 & 1 \\
\hline Copper & - & 6 & 1 \\
\hline Water & - & 80 & 1 \\
\hline PVC & 100 & 3,4 & 1 \\
\hline Ground & - & - & 1 \\
\hline
\end{tabular}


Different geometries have been used to better model the defects that may occur during the production and operation of medium voltage underground cables, and materials such as water, copper, transformer oil, fiber and air, which are frequently encountered in practical applications, have been preferred.

\subsection{Analysis of the Effects of Defects in Different Forms on Electric Field Distribution}

All scenarios listed below are examined in case of a defect in the cable such as air, fiber-like, copper-like, transformer oil, water.

1) Spherical Form Defects

a) $0,25 \mathrm{~mm}$ radius

b) $0,375 \mathrm{~mm}$ radius

2) Cubic Form Defects

a) $0,44 \mathrm{~mm}$ edge

b) 0,66 mm edge

3) Tetrahedral Form Defects

a) 0,66 mm edge

b) $1 \mathrm{~mm}$ edge

4) Comparative Defect Forms for Air Gap

5) Comparative Defect Forms for Water Droplet

The distances for the three defects in the cable insulator are as follows: the geometric center of the defects located in the middle of the cable insulator is at the midpoint of the insulator, and the distance between the defects close to the cable insulator surfaces and the insulator surface is $0,1 \mathrm{~mm}$. All values taken for plotting graphs created by using red lines are shown in Fig. 2.

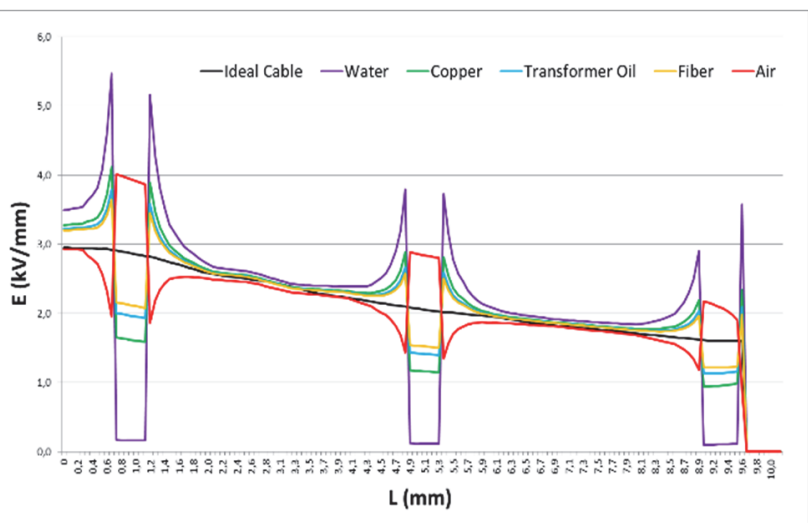

(a)

Figure 3 Comparative electric field distributions for different foreign particles (defects) having spherical form in the XLPE cable: (a) $0,25 \mathrm{~mm}$ spherical defect (b) $0,375 \mathrm{~mm}$ spherical defect

It is clearly seen that the distribution of the electric field within the defect is logarithmically reduced due to the shape being cylindrical. It can be seen that the defect being in different positions in the insulator affects the electric field distribution in a similar way. Due to the difference of dielectric permittivities for other materials, it has been observed that although the electric field change is different, there are different forms of behaviour. Of course, the worst case can be said to be the case where the defect is made up of water droplets.

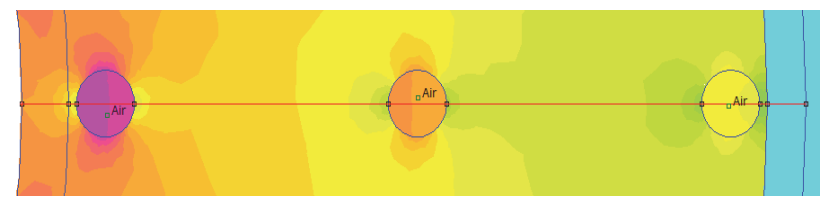

(a)

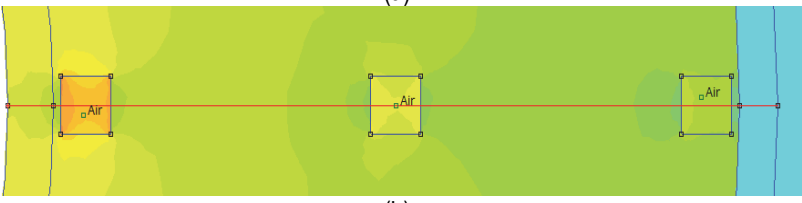

(b)

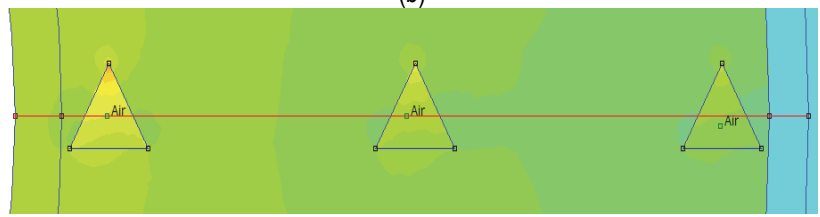

(c)

Figure 2 Forms of defect: (a) Spherical form (b) Cubic form (c) Tetrahedral form

\subsubsection{Electric Field Distributions for Spherical Defects}

In this section, it is assumed that the defect in the cable insulation is spherical. In the case of spherical defects with radius length of $0,25 \mathrm{~mm}$ and $0,375 \mathrm{~mm}$, electric field distribution graphs are given in Fig. 3a and Fig. 3b, respectively.

The electric field analysis of the cable having defects in a cylindrical form in the cable insulator was made for a total of five different cable dielectric materials. Although the distribution of the electric field on the surface of the defect, which contains air, has decreased, the distribution of the electric field has increased in the defect and reached $3 \mathrm{kV} / \mathrm{mm}$.

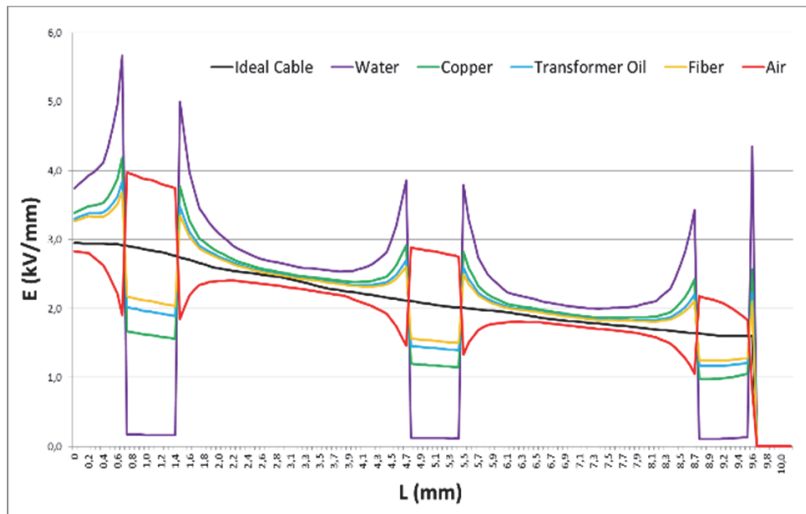

L (mm)

\subsubsection{Electric Field Distributions for Cubic Defects}

In the case of cubic defects with an edge length of 0,44 $\mathrm{mm}$ and $0,66 \mathrm{~mm}$, electric field distribution graphs are given in Fig. 4a and Fig. 4b, respectively.

Since the shape is cubic, it is clearly seen that the distribution of electric field in the defect does not decrease logarithmically, and that it exhibits different behaviours depending on the type of material in the defect. For example, the distribution of the electric field in the defect with water droplet shows a linear behaviour, while the distribution of the electric field in the defect with the air exhibits parabolic behaviour. 


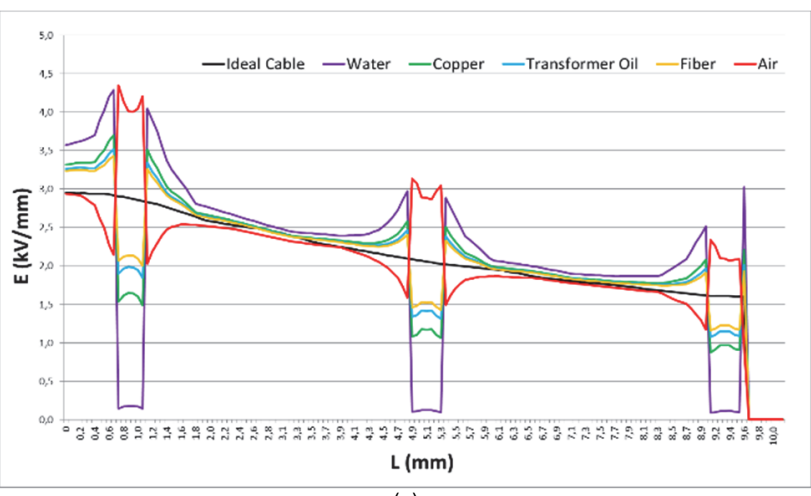

(a)

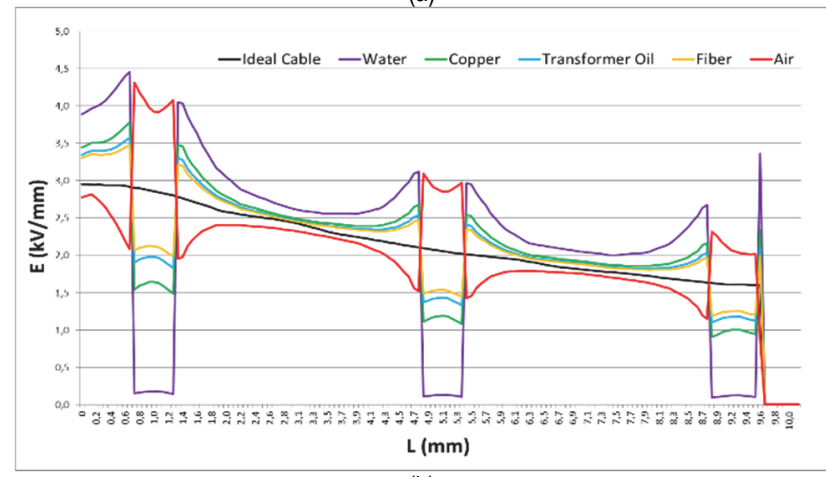

(b)

Figure 4 Comparative electric field distributions for different foreign particles (defects) having cubic form in the XLPE cable: (a) 0,44 mm edge cubic defect (b) $0,66 \mathrm{~mm}$ edge cubic defect

\subsubsection{Electric Field Distributions for Tetrahedral Defects}

In the case of tetrahedral defects with an edge length of $0,66 \mathrm{~mm}$ and $1 \mathrm{~mm}$, electric field distribution graphs are given in Fig. 5a and Fig. 5b, respectively.

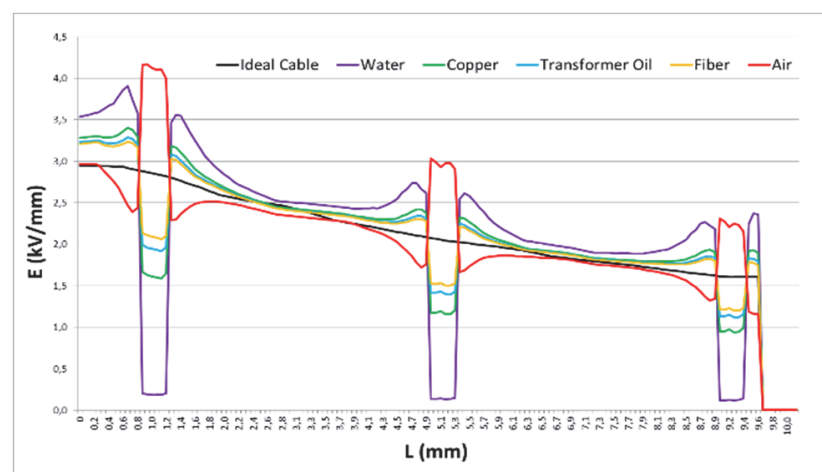

(a)

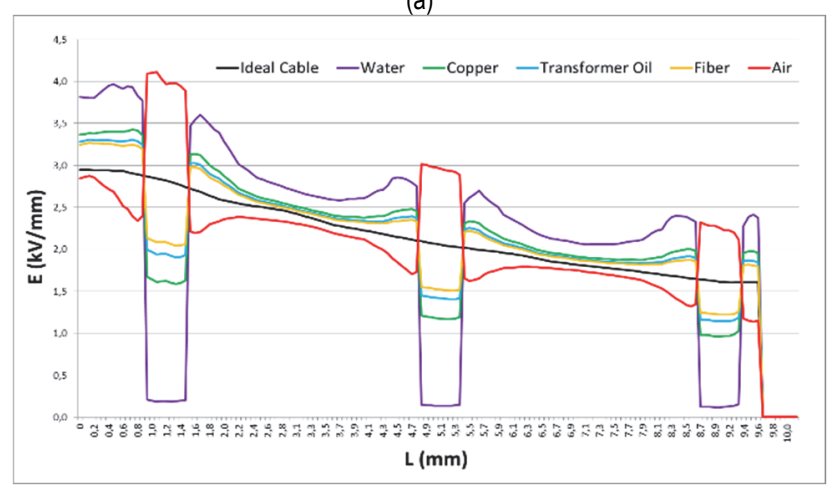

(b)

Figure 5 Comparative electric field distributions for different foreign particles (defects) having tetrahedral form in the XLPE cable: (a) 0,66 mm edge tetrahedral defect (b) $1 \mathrm{~mm}$ edge tetrahedral defect
When a defect in the form of a triangular prism occurs in the cable insulator, it is understood that the distribution of the electric field in the defect surfaces and within the defect exhibits an unbalanced behaviour.

The difference between the behaviour of the defect being close to the conductor and its close to the shield and the effect of the defective material on this behaviour can be clearly seen. For example, when it has been looked at the distribution of the electric field in the defect that contains air, it can be seen that the electric field distribution in the defect becomes linear as the defect moves away from the conductor. However, it is striking that the distribution of the electric field in the defect with water droplet shows a linear behaviour independent of the location of the defect.

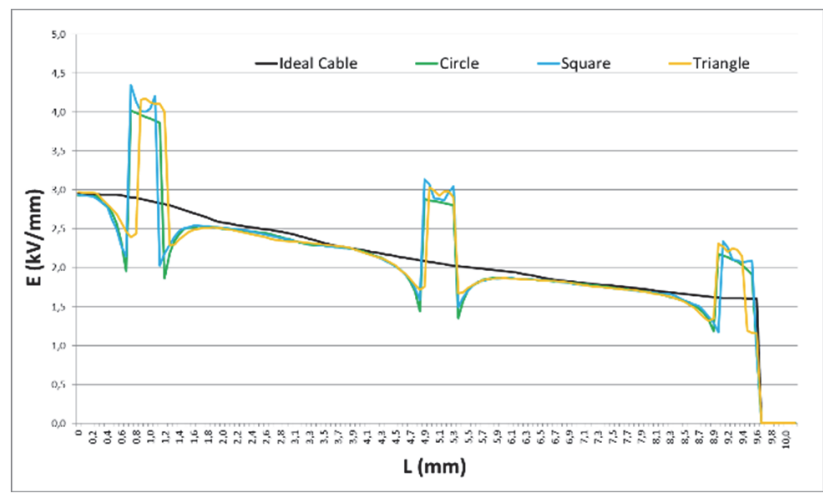

(a)

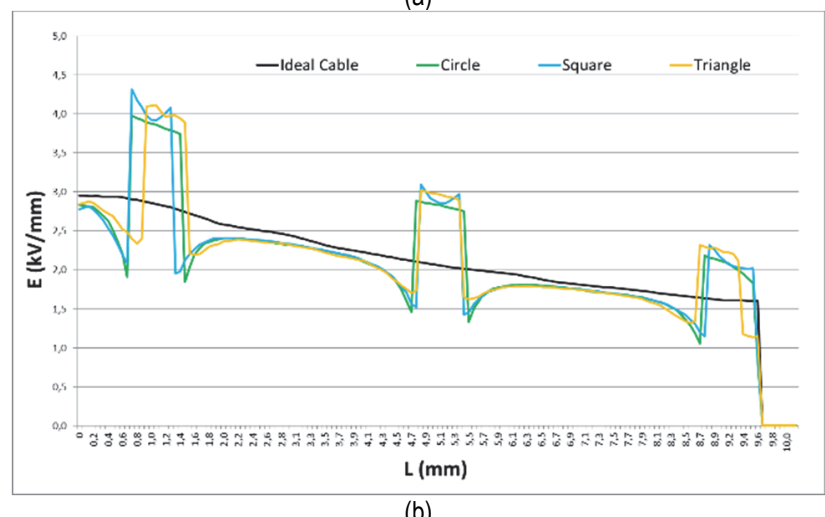

Figure 6 Comparative electric field distributions for air gap defect in different form in the XLPE cable: (a) 0,196 $\mathrm{mm}^{2}$ defect area (b) 0,442 $\mathrm{mm}^{2}$ defect area

\subsubsection{Electric Field Distributions for Air Gap Defect in Comparative Forms}

It is understood from the graphs in Fig. 2a, Fig. 3a and Fig. 4a that the material is also important in comparing the spherical, cubic, tetrahedral form defects. As seen from previous scenarios, electric field distribution graphs for defects of different forms of air gap are shown in this section. In the case of air gap defect for all the defect forms, electric field distribution graphs are given in Fig. 6a and $6 \mathrm{~b}$, respectively. The most important conclusion that can be drawn from the graphs, which allows us to see the distribution of the electric field in the cable insulator, is that the defect that contains air in different forms is very effective on the electric field distribution. It is clearly seen that the distribution of the electric field in the spherical defect is logarithmic, while it shows a parabolic behaviour in the cubic defect. If the electric field changes on the defect surface are considered to be similar, the only 
interpretation that can be made here is that the circular defect may be less harmful than other defects.

\subsubsection{Electric Field Distributions for Water Droplet Defect in Comparative Forms}

As seen from previous scenarios, electric field distribution graphs for defects of different forms of water droplet are shown in this section. The cross-section areas of spherical, cubic and tetrahedral defects are equal to each other. In the case of a water droplet defect for all the defect forms, electric field distribution graphs are given in Fig. 7a and Fig. $7 b$ respectively.

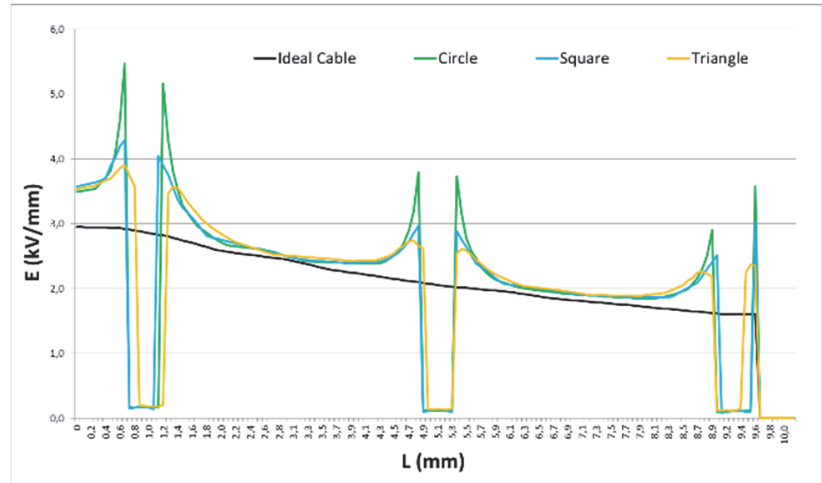

(a)

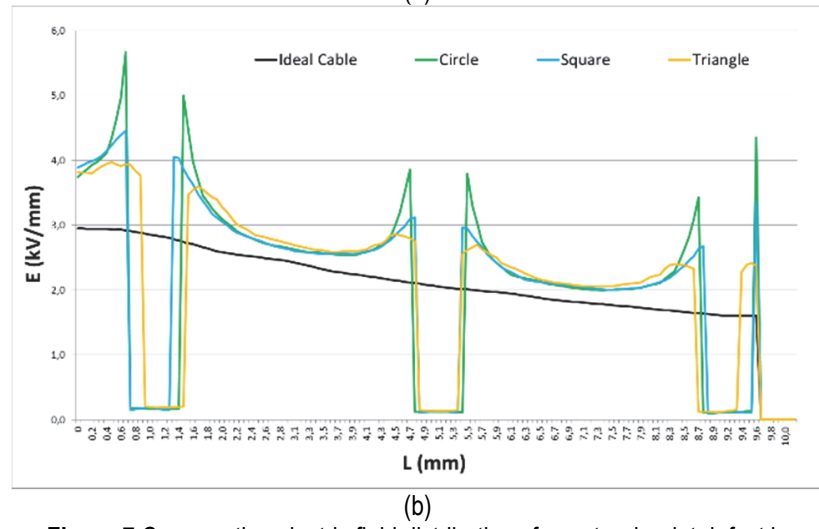

Figure 7 Comparative electric field distributions for water droplet defect in different form in the XLPE cable: (a) 0,196 $\mathrm{mm}^{2}$ defect area (b) 0,442 $\mathrm{mm}^{2}$ defect area

In materials such as water droplets, which have a dielectric permeability that is much more than the relative dielectric permeability value of the cable insulator, it is clearly seen that the electric field distribution in the defect is independent of the form of the defect and exhibits a similar behaviour. But the most important point to note here is the difference in behaviour in the electric field distribution on the surface of the defect. It should be noted here that the defect in its spherical form is more dangerous than the defects in other form.

\subsection{Magnetic Field Analysis of XLPE Cable with a Single- core or Three-core}

All the scenarios were analyzed in the cylindrical coordinate system, under the nominal voltage with cable depth of $1000 \mathrm{~mm}$, the nominal current flow through the conductor, and the boundary conditions that would occur if the cable shield was grounded. The conditions in these scenarios are detailed below.
1) A Single-core Cable

a) Balanced load condition

b) Unbalanced load condition

2) A Three-core Cable

a) Balanced load condition

b) Unbalanced load condition

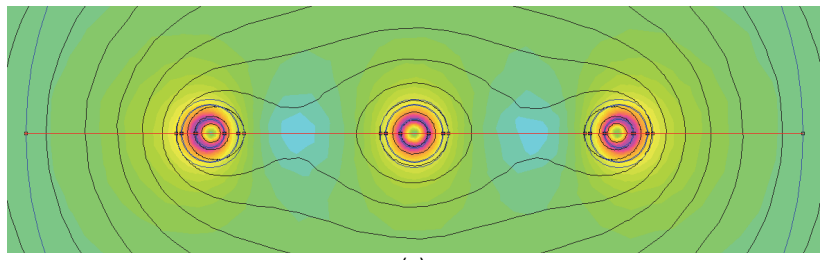

(a)

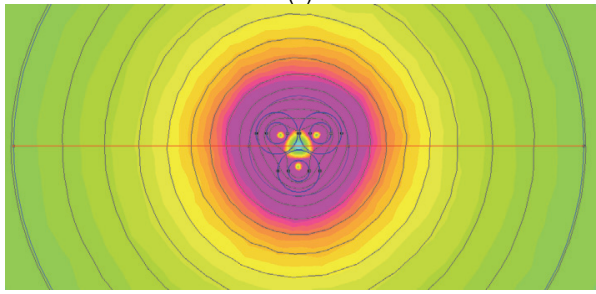

(b)

Figure 8 Magnetic field distributions obtained in FEMM: (a) $3 \times(1 \times 240 / 25)$ $\mathrm{mm}^{2}$ XLPE cable (b) $3 \times 240 / 25 \mathrm{~mm}^{2}$ XLPE cable

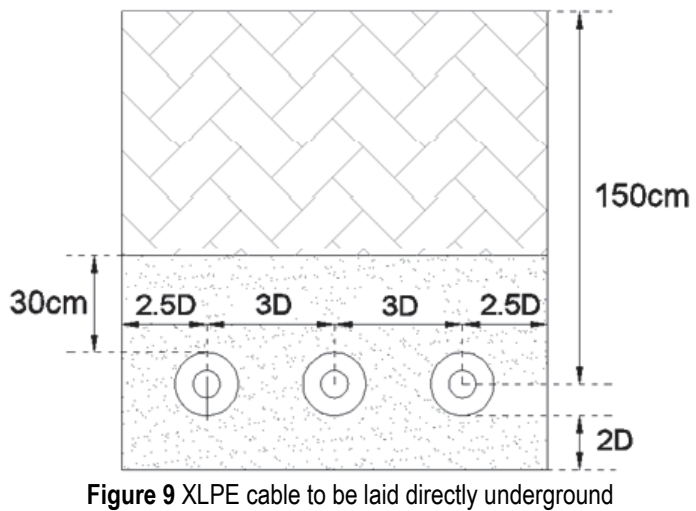

The magnetic field analysis was performed for the case where CableSC and CableTC shown in Fig. 8, were laid underground as seen in Fig. 9. In this scenario, CableSC and CableTC balanced and unbalanced loading cases were investigated. Balanced load can be defined as current flow of $575 \mathrm{~A}$ through all cables, unbalanced load can be defined as current flow of 460 A - 575 A - 690 A through cables. In the following figures, the magnetic field scatter plots of the CableSC and the CableTC in the case of balanced load and the magnetic field scatter plots of both cables in the case of unbalanced load are shown. All values taken for plotting graphs are created by using red lines.

\subsubsection{Magnetic Field Distributions for Balanced Load Conditions}

In this section, magnetic field analyses were performed in the event that the rated current flows through the CableSC and CableTC, which are buried directly under the ground as indicated in Fig. 8. In the case of a $3 \times(1 \times$ $240 / 25) \mathrm{mm}^{2}$ and $3 \times 240 / 25 \mathrm{~mm}^{2}$ XLPE cable balanced load conditions, magnetic field distribution graphs are given in Fig. 10a and Fig. 10b, respectively.

The magnetic field changes due to the current value vary as expected. It is seen that the defect occurring in the 
cable insulator does not affect the magnetic field distribution, or even the magnetic permeability coefficient of the defect does not affect the magnetic field distribution because of changing the shape of the defect or changing the magnitude of the defect or even the type of material contained in the defect.

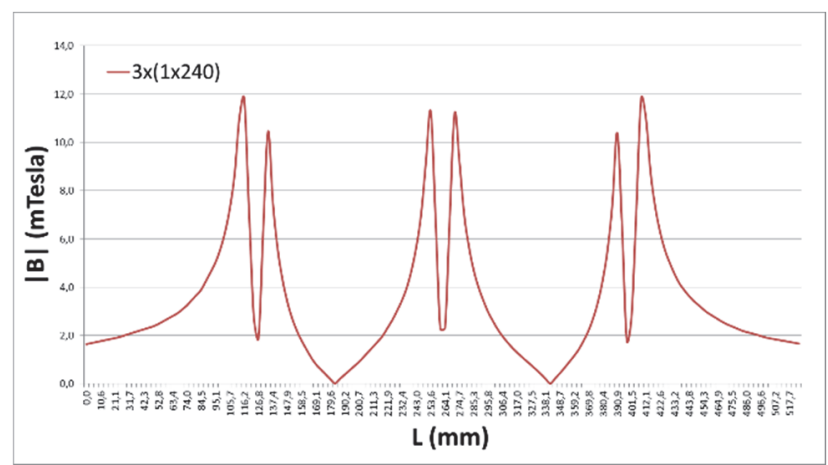

(a)

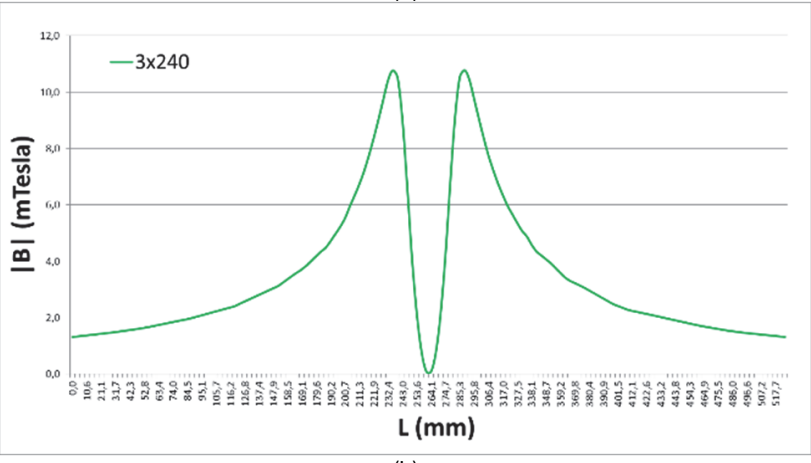

(b)

Figure 10 Magnetic field distributions: (a) $3 \times(1 \times 240 / 25) \mathrm{mm}^{2}$ XLPE cable (b) $3 \times 240 / 25 \mathrm{~mm}^{2}$ XLPE cable

For this reason, considering the distribution of currentinduced magnetic field will again change from current, an investigation was carried out on unbalanced loads occurring in practice. It can be seen in the graphs in Fig. $10 \mathrm{a}$ and Fig. 10b that the magnetic field distributions of CableSC and CableTC are different, generating magnetic field of $12 \mathrm{mT}$.

\subsubsection{Magnetic Field Distributions for Unbalanced Loading Conditions}

Unbalanced loading of underground cables due to onephase loads is quite common. Therefore, the magnetic field analysis of the cables for unbalanced load cases has been done in this section. In the case of CableSC and CableTC unbalanced load conditions, magnetic field distribution graphs are given in Fig. 11.

It can be seen in the graphs in Fig. 11 that the unbalanced load of the CableTC is less varied than the CableSC. It is a very common problem to draw different values from each phase in electricity distribution. To examine the effect of this problem on the cable, the unbalanced load is sampled and the magnetic field distribution is examined. CableSC and CableTC behaved as expected.

When the superficial magnetic field distributions were neglected, it was the information obtained from the previous section where both cables were exposed to a similar value magnetic field for a balanced load condition.
However, in case of unbalanced load, CableSC is exposed to more magnetic fields. The reason for this may be the physical structure of CableTC. Three conductors located much closer to each other provide an advantage due to the fact that the magnetic field is processed vectorly.

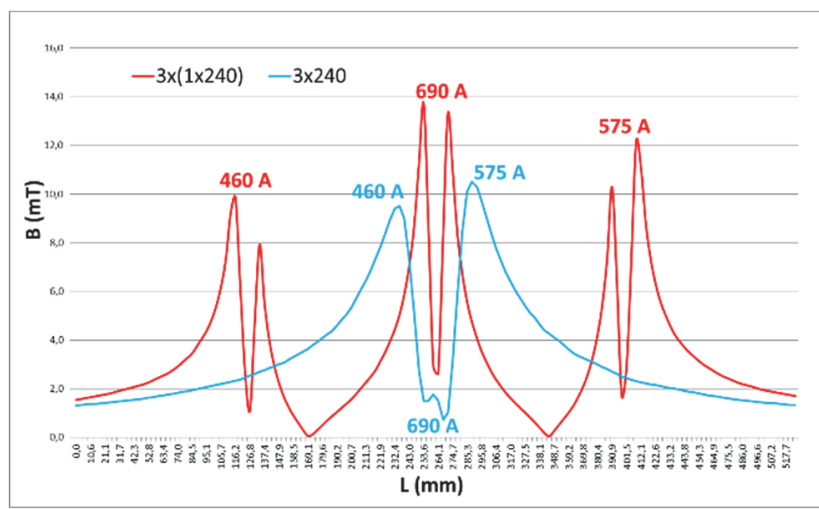

Figure 11 Magnetic field distributions for unbalanced load conditions

\section{DISCUSSION}

Considering the logarithmic reduction of the electric field distributions of the ideal cable starting from $3 \mathrm{kV} / \mathrm{mm}$, it can be considered that there is no negative effect on the cable aging and life span in the short-term. The effects of defects that may occur during the production phase of power cables on electric and magnetic field distributions are investigated. These distributions are given for three different forms of foreign particles scenarios respectively; cable with a spherical defect, cable with a cubic form defect and cable with a tetrahedral defect.

All scenarios are investigated in the cases near the conductor surface, in the middle of insulator, and near the insulator surface. In all the drawings, the distance between the conductive outer surface and the defect is $0,1 \mathrm{~mm}$ and the distance between the insulator outer surface and the defect is $0,1 \mathrm{~mm}$.

Electric field values for all different forms: near the conductor surface (NCS), in the middle of insulator (MOI), near the insulator surface (NIS) are shown in Tab. 3, Tab. 4 and Tab. 5, respectively.

Table 3 Electric field intensity values according to defects in spherical form

\begin{tabular}{|l|c|c|c|}
\hline \multirow{2}{*}{\multicolumn{1}{|c|}{ Material }} & \multicolumn{3}{|c|}{$\mathrm{E} / \mathrm{kV} / \mathrm{mm}$} \\
\cline { 2 - 4 } & NCS & MOI & NIS \\
\hline Air & 4 & 2,9 & 2,1 \\
\hline Fiber & 2,2 & 1,5 & 1,2 \\
\hline Transformer Oil & 2 & 1,4 & 1,1 \\
\hline Copper & 1,7 & 1,1 & 0,9 \\
\hline Water & 0,1 & 0,1 & 0,1 \\
\hline
\end{tabular}

Table 4 Electric field intensity values according to defects in cubic form

\begin{tabular}{|l|c|c|c|}
\hline \multirow{2}{*}{ Material } & \multicolumn{3}{|c|}{ E / kV/mm } \\
\cline { 2 - 4 } & NCS & MOI & NIS \\
\hline Air & 4,3 & 3,1 & 2,25 \\
\hline Fiber & 2,1 & 1,5 & 1,2 \\
\hline Transformer Oil & 2 & 1,4 & 1,1 \\
\hline Copper & 1,6 & 1,1 & 0,9 \\
\hline Water & 0,2 & 0,1 & 0,1 \\
\hline
\end{tabular}

In the section 3.1.1, when a defect in spherical form with air gap was near the conductor surface in the cable, the electric field value increased by $33 \%$ from $3 \mathrm{kV} / \mathrm{mm}$ to $4 \mathrm{kV} / \mathrm{mm}$. When a defect in spherical form with air gap was 
in the middle of insulator in the cable, the electric field value increased by $45 \%$ from $2 \mathrm{kV} / \mathrm{mm}$ to $2,9 \mathrm{kV} / \mathrm{mm}$. When a defect in spherical form with air gap was near the insulator surface in the cable, the electric field value increased by $40 \%$ from $1,5 \mathrm{kV} / \mathrm{mm}$ to $2,1 \mathrm{kV} / \mathrm{mm}$.

Table 5 Electric field intensity values according to defects in tetrahedral form

\begin{tabular}{|l|c|c|c|}
\hline \multirow{2}{*}{\multicolumn{1}{c|}{ Material }} & \multicolumn{3}{|c|}{$E / \mathrm{kV} / \mathrm{mm}$} \\
\cline { 2 - 4 } & NCS & MOI & NIS \\
\hline Air & 4,2 & 3 & 2,25 \\
\hline Fiber & 2,1 & 1,5 & 1,3 \\
\hline Transformer Oil & 1,9 & 1,4 & 1,2 \\
\hline Copper & 1,6 & 1,2 & 1 \\
\hline Water & 0,2 & 0,1 & 0,1 \\
\hline
\end{tabular}

When a defect in cubic form with air gap was near the conductor surface in the cable, the electric field value increased by $43 \%$ from $3 \mathrm{kV} / \mathrm{mm}$ to $4,3 \mathrm{kV} / \mathrm{mm}$. When a defect in cubic form with air gap was in the middle of insulator in the cable, the electric field value increased by $55 \%$ from $2 \mathrm{kV} / \mathrm{mm}$ to $3,1 \mathrm{kV} / \mathrm{mm}$. When a defect in cubic form with air gap was near the insulator surface in the cable, the electric field value increased by $50 \%$ from 1,5 $\mathrm{kV} / \mathrm{mm}$ to $2,25 \mathrm{kV} / \mathrm{mm}$.

In the section 3.1.3, when a defect in tetrahedral form with air gap was near the conductor surface in the cable, the electric field value increased by $40 \%$ from $3 \mathrm{kV} / \mathrm{mm}$ to $4,2 \mathrm{kV} / \mathrm{mm}$. When a defect in tetrahedral form with air gap was in the middle of insulator in the cable, the electric field value increased by $50 \%$ from $2 \mathrm{kV} / \mathrm{mm}$ to $3 \mathrm{kV} / \mathrm{mm}$. When a defect in tetrahedral form with air gap was near the insulator surface in the cable, the electric field value increased by $50 \%$ from $1,5 \mathrm{kV} / \mathrm{mm}$ to $2,25 \mathrm{kV} / \mathrm{mm}$.

In the section 3.2 , the magnetic field occurring in a single core cable appears to be $10 \%$ more than in a three core cable. It can be seen very clearly that a three core cable generates $40 \%$ less magnetic field in case of unbalanced load even when the surface distributions are neglected.

\section{CONCLUSION}

The presence of foreign particles in the cable causes a serious change in the electric field. Partial discharges that may occur due to electric field changes can cause foreign matter to move in the form of tree branches. The treeing behaviour may lead to the repetition of partial discharges and therefore the destruction of the cable insulation and the aging of the cable rapidly. As a result, the cable, cable terminations, and cable joints can be forced further and cause the insulation to fail. The analysis was carried out with the finite element method, assuming that the cable is two-dimensional and that the stress is ideal (that is, it has no problem in terms of power quality).

In this study, not only the location, but also the defect forms were examined. Analyses were performed using defects having different forms such as spherical, cubic and tetrahedral. Firstly, the analysis of the defects of different forms of different materials were carried out and detailed in the graphs. Then, comparative graphs of spherical, cubic and tetrahedral forms were examined for the defect of the same material. As can be seen from the graphs, although the location of the defects is in the same place, the distortion patterns of the electric field distribution graphs are completely different. For example, when we look closely at the Fig. 6a, we can say that the defect in the cubic form changes more than the other defect forms for the defect near the conductor surface. The defect in the cubic form causes the electric field of $2,9 \mathrm{kV} / \mathrm{mm}$ in the ideal cable to decrease to $1,9 \mathrm{kV} / \mathrm{mm}$ and increase to $4,4 \mathrm{kV} / \mathrm{mm}$.

One of the results that can be obtained from this section is that the effect of the defect form on the electric field distribution is important. In the light of the data obtained, it is necessary to compare the defect forms from bad to good; spherical, cubic and tetrahedral. However, it is another conclusion that evaluating the defect form alone will not always give correct results, and that the type of material that creates the defect may affect the electric field distribution in different defect forms differently.

Since the magnetic field analysis performed in cases where there is defect in the ideal cable does not give an extraordinary result, magnetic field analysis was performed for balanced and unbalanced loading conditions using single and three core XLPE cable. The most striking feature for the analysis of the unbalanced state, rather than the expected results of the magnetic field analysis for the balanced state, is the change in the distribution of the magnetic field formed in the tri-core XLPE cable. This change in the magnetic field may have an effect on the cable's temperature and current carrying capacity.

According to the results obtained, in order to prevent deformation problems during production, the procedures that must be followed at every stage of production must be carefully followed and quality control must be done precisely. During the operation of the cable, it is necessary to find competent people in the maintenance activities to be carried out in the field, to perform the maintenance processes meticulously and to evaluate the results of the control tests to be performed after maintenance.

The effects of voltage types such as overvoltage and impact voltage on defects in the insulation material can be investigated in our future studies.

\section{REFERENCES}

[1] Kovač, Z., Knežević, G., \& Topić, D. (2013). Modelling of Power System Reliability Assessment. Technical Gazette 20(1), 93-98.

[2] Kocatepe, C., Arikan, O., Kumru, C. F., \& Orhan, O. D. (2012). The Effect of Insulation Problems in High Voltage Cables on the Electric Field Distribution. ELECO 2012 National Symposium on Electrical-Electronics and Computer Engineering, 1-5.

[3] Uydur, C. C., Arikan, O., \& Kalenderli, O. (2018). The Effect of Insulation Defects on Electric Field Distribution of Power Cables. Proceedings of the 2018 IEEE International Conference on High Voltage Engineering and Application (ICHVE), Athens, Greece, 1-4. https://doi.org/10.1109/ICHVE.2018.8641936

[4] Lachini, S., Gholami, A., \& Mirzaie, M. (2010). Determining Electric Field Distribution in High Voltage Cable in Presence of Cavity. Universities Power Engineering Conference (UPEC), U. K., 1-7.

[5] Liu, T., Lv, Z., Wang, Y., Wu, K., Dissado, L. A., Peng, Z., \& Li, R. (2013). A New Method of Estimating the Inverse Power Law Ageing Parameter of XLPE Based on StepStress Tests. IEEE Conference on Electrical Insulation and Dielectric Phenomena, Schenzhen, China. https://doi.org/10.1109/CEIDP.2013.6748201

[6] Stancu, C., Notingher, P., Ciuprina, F., Notingher Jr. P., 
Castellon, J., Agnel, S., \& Toureille, A. (2009). Computation of the Electric Field in Cable Insulation in the Presence of Water Trees and Space Charge. IEEE Transactions on Industry Applications, 45(1), 30-43. https://doi.org/10.1109/TIA.2008.2009659

[7] Hvidsten, S., Holmgren, B., Adeen, L., Wetterstrom, J., (2005). Condition Assessment of 12-and 24-kV XLPE Cables Installed During the 80s. Results from a Joint Norwegian/Swedish Research Project. IEEE Electrical Insulation Magazine, 21(6), 17-23. https://doi.org/10.1109/MEl.2005.1541485

[8] Zhang, D., Zhang, Z., Jiang, X., Shu, L., \& Wu, B. (2018) Simulation Study on the Effects of DC Electric Field on Insulator Surface Pollution Deposit. Energies, 11, 626-637. https://doi.org/10.3390/en11030626

[9] Zigan, L. (2018). Overview of Electric Field Applications in Energy and Process Engineering. Energies, 11, 1161-1193. https://doi.org/10.3390/en11061361

[10] Medoukali, H., Guibadj, M., Zegnini, B. (2015). Study of Electrical Constraints within Cavities in High Voltage Cables. International Journal of Computational and Experimental Science and Engineering (IJCESEN), 1(1), 30-35. https://doi.org/10.22399/ijcesen.194370

[11] Fan, Y., Wang, J., Hong, Z., Qin, Q., Zhou, M., \& Cai, L. (2015). Analysis of Electric Field Distribution in XLPE Insulation of DC Submarine Cable. International Conference on Insulated Power Cables, Versailles, France, $1-5$.

[12] Alsharif, M., Wallace, P., Hepburn, D., \& Zhou, C. (2012). FEM Modelling of Electric Field and Potential Distributions of MV XLPE Cables Containing Void Defect. Excerpt from the Proceedings of the 2012 COMSOL Conference, Milan, Italy, 1-4.

[13] Sharif, M. H. M., Jamail, N. A.M. Othman, N. A., \& Kamarudin, M. S. (2017). Analysis of Electric Field and Current Density on XLPE Insulator. International Journal of Computational and Experimental Science and Engineering (IJCESEN), 7(6), 3095-3104. https://doi.org/10.11591/ijece.v7i6.pp3095-3104

[14] Korzhov, A. (2018). Effect of Magnetic Field on Partial Discharge Parameters in Power Cables and on the Breakdown Characteristics of Impregnated Paper Insulation. Journal of Electrostatics, 96, 169-176. https://doi.org/10.1016/j.elstat.2018.11.001

[15] Geng, J., Qin, Y., Lv, F., Yao, X., \& Ding, Y. (2018). Electric Field Distribution and Switching Impulse Discharge under Shield Ball Surface Scratch Defect in an UHVDC Hall. Energies, 11, 1408-1417. https://doi.org/10.3390/en11061408

[16] Illias, H. A., Chen, G., \& Lewin, P. L. (2009). Partial discharge measurements for spherical cavities within solid dielectric materials under different stress and cavity conditions. 2009 IEEE Conference on Electrical Insulation and Dielectric Phenomena, Virginia Beach, VA, 388-391. https://doi.org/10.1109/CEIDP.2009.5377831

[17] Illias, H. A., Chen, G., \& Lewin, P. L. (2009). Modelling of partial discharge activity in different spherical cavity sizes and locations within a dielectric insulation material. 2009 IEEE 9th International Conference on the Properties and Applications of Dielectric Materials, Harbin, 485-488. https://doi.org/10.1109/ICPADM.2009.5252384

[18] Illias, H. A., Chen, G., \& Lewin, P. L. (2010). Modelling of partial discharge behaviour in a spherical cavity within a solid dielectric material as a function of temperature. 2010 Annual Report Conference on Electrical Insulation and Dielectic Phenomena, West Lafayette, IN, 1-4. https://doi.org/10.1109/CEIDP.2010.5723968

[19] Illias, H. A., Chen, G., \& Lewin, P. L. (2011). Partial discharge behavior within a spherical cavity in a solid dielectric material as a function of frequency and amplitude of the applied voltage. IEEE Transactions on Dielectrics and
Electrical Insulation, 18(2), 432-443. https://doi.org/10.1109/TDEl.2011.5739447

[20] Illias, H. A., Chen, G., \& Lewin, P. L. (2011). Modeling of partial discharge activity in spherical cavities within a dielectric material. IEEE Electrical Insulation Magazine, 27(1), 38-45. https://doi.org/10.1109/MEI.2011.5699446

[21] Illias, H. A., Chen, G., \& Lewin, P. L. (2011). Partial discharge behaviour within two spherical cavities in a dielectric material. 2011 Annual Report Conference on Electrical Insulation and Dielectric Phenomena, Cancun, 456-459, https://doi.org/10.1109/CEIDP.2011.6232693

[22] Illias, H., Teo, S. Y., Bakar, A. H. A., Mokhlis, H., Chen, G., \& Lewin, P. L. (2012). Partial discharge patterns in high voltage insulation. 2012 IEEE International Conference on Power and Energy (PECon), Kota Kinabalu, 750-755. https://doi.org/10.1109/PECon.2012.6450316

[23] Illias, H., Low, T. J., Bakar, A. H. A., \& Mokhlis, H. (2012). Partial discharge simulation under various applied voltage waveforms. 2012 IEEE International Conference on Power and Energy (PECon), Kota Kinabalu, 967-972. https://doi.org/10.1109/PECon.2012.6450358

[24] Illias, H. A., Ng, Q. L., Bakar, A. H. A., Mokhlis, H., \& Ariffin, A. M. (2012). Electric field distribution in $132 \mathrm{kV}$ XLPE cable termination model from finite element method. 2012 IEEE International Conference on Condition Monitoring and Diagnosis, Bali, 80-83. https://doi.org/10.1109/CMD.2012.6416254

[25] Illias, H. A., Lee, Z. H., Bakar, A. H. A., Mokhlis, H., Chen, G., \& Lewin, P. L. (2012). Electric field distribution in 132 $\mathrm{kV}$ one piece premolded cable joint structure. 2012 IEEE International Conference on Condition Monitoring and Diagnosis, Bali, 643-646. https://doi.org/10.1109/CMD.2012.6416227

[26] Illias, H. A., Lee, Z. H., Bakar, A. H. A., Mokhlis, H., \& Ariffin, A. M. (2012). Distribution of electric field in medium voltage cable joint geometry. 2012 IEEE International Conference on Condition Monitoring and Diagnosis, Bali, 1051-1054. https://doi.org/10.1109/CMD.2012.6416337

[27] Illias, H. A. et al., (2013). Modelling of partial discharge pulses in high voltage cable insulation using finite element analysis software. 2013 IEEE Electrical Insulation Conference (EIC), Ottawa, ON, 52-56 https://doi.org/10.1109/EIC.2013.6554201

[28] Illias, H. A., Tunio, M. A., Mokhlis, H., Chen, G., \& Bakar, A. H. A. (2015). Experiment and modeling of void discharges within dielectric insulation material under impulse voltage. IEEE Transactions on Dielectrics and Electrical Insulation, 22(4), 2252-2260. https://doi.org/10.1109/TDEI.2015.004817

[29] Illias, H. A., Tunio, M. A., Bakar, A. H. A., Mokhlis, H., \& Chen, G. (2012). Partial discharge phenomena within an artificial void in cable insulation geometry: experimental validation and simulation. IEEE Transactions on Dielectrics and Electrical Insulation, 23(1), 451-459. https://doi.org/10.1109/TDEl.2015.005155

[30] Meunier, G. (2008).The Finite Element Method for Electromagnetic Modeling. Wiley Publishing, New Jersey, United States. https://doi.org/10.1002/9780470611173 


\section{Contact information:}

Cihat Cagdas UYDUR, Lecturer, PhD Student

(Corresponding author)

Technical Sciences Vocational School,

Trakya University,

Edirne, Turkey

E-mail: ccagdasuydur@trakya.edu.tr

Oktay ARIKAN, Associate professor, PhD

Department of Electrical Engineering,

Yildiz Technical University,

Istanbul, Turkey

E-mail: oarikan@yildiz.edu.tr

Ozcan KALENDERLI, Prof. PhD

Department of Electrical Engineering,

Istanbul Technical University,

Istanbul, Turkey

E-mail: kalenderli@itu.edu.tr 